\title{
Japanese Legacy Cohorts: Six-Prefecture Cohort Study (Hirayama Cohort Study)
}

\author{
Suminori Akiba ${ }^{1,2}$ and Yoshihide Kinjo ${ }^{3}$ \\ ${ }^{1}$ Specially Appointed Professor, Hirosaki University, Aomori, Japan \\ ${ }^{2}$ Professor Emeritus, Kagoshima University, Kagoshima, Japan \\ ${ }^{3}$ Okinawa Prefectural College of Nursing Graduate Study in Health Nursing, Naha, Japan
}

Received April 23, 2019; accepted November 23, 2019; released online December 14, 2019

\begin{abstract}
Late Dr Takeshi Hirayama and his colleagues conducted a mortality follow-up of a large-scale cohort in six prefectures in Japan. This study is called the six-prefecture cohort study or Hirayama Cohort Study. The study subjects were residents aged 40 years or older at the baseline survey in 1965 , which covered $94.8 \%$ of residents identified in the study area by the National Census conducted on October 1, 1965. The mortality of 264,118 cohort members was followed until the end of 1982 . One of the most important findings made by this study was an association between second-hand smoke exposure and lung cancer. This finding is the origin of the worldwide spread of smoking ban in indoor public venues and workplaces. Other major findings obtained from the study are also briefly described in this article.
\end{abstract}

Key words: cohort study; smoking; cancer epidemiology

Copyright $\odot 2019$ Suminori Akiba et al. This is an open access article distributed under the terms of Creative Commons Attribution License, which permits unrestricted use, distribution, and reproduction in any medium, provided the original author and source are credited.

\section{ORIGIN OF THE COHORT}

After conducting more than 30 case-control studies in Japan during the period between 1952 and 1964, late Dr Takeshi Hirayama (Figure 1) felt it necessary to take another epidemiological approach. ${ }^{1}$ Inspired by large-scale cohort studies $^{2-6}$ conducted in North America and the United Kingdom in the 1950s, Dr Hirayama decided to start the six-prefecture cohort study (Hirayama Cohort Study) in Japan in order to examine the cause-specific mortality in relation to lifestyles such as cigarette smoking, alcohol drinking and dietary habits. ${ }^{1,7}$ Main features of Hirayama Cohort Study were that it adopted a census populationbased approach and targeted a wide range of lifestyles: tobacco smoking, alcohol drinking, dietary intake, and typical lifestyles in Japan such as Japanese tea drinking.

\section{BUILDING AND MAINTAINING THE COHORT}

\section{Study populations and areas}

From October to December 1965, a questionnaire survey (the baseline survey) of all residents aged 40 or older was conducted in 29 public health districts in six prefectures (Miyagi, Aichi, Osaka, Hyogo, Okayama and Kagoshima). Those prefectures (Figure 2), selected by Dr Hirayama, geographically represent the entire Honshu Island, one of five major islands of the archipelago of Japan. ${ }^{7}$ From 7 prefectures in Kyushu Island, Kagoshima Prefecture was selected. The remaining main islands, which are Hokkaido, Shikoku, and Okinawa, were not covered.

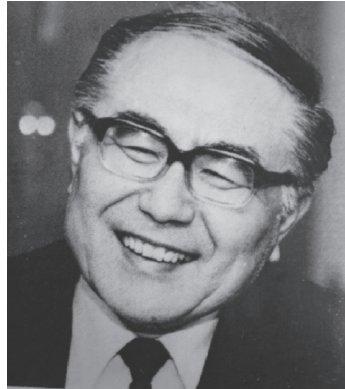

Takeshi Hirayama (1923.1.1 1995.10.26)

Source: A journey of solving the mystery of cancer: Sketch by Dr. Takeshi Hirayama Edit / Publish by Institute of Preventive Oncology (December 31, 1995)

Figure 1.

\section{Questionnaire}

The baseline survey used a one-page questionnaire to obtain information on various factors, including tobacco smoking, alcohol drinking, dietary habits, and occupation, and, in addition, for women, their reproductive history. Questions on smoking were about the number of cigarettes smoked per day, the types of tobacco, age when starting smoking, smoking regularly or not, and, for ex-smokers, years since cessation of smoking. The amount of daily cigarette consumption was obtained from $94 \%$ of current daily cigarette smokers. ${ }^{8}$ An English translation of the questionnaire is given in an article written by Dr Hirayama. ${ }^{1}$ 


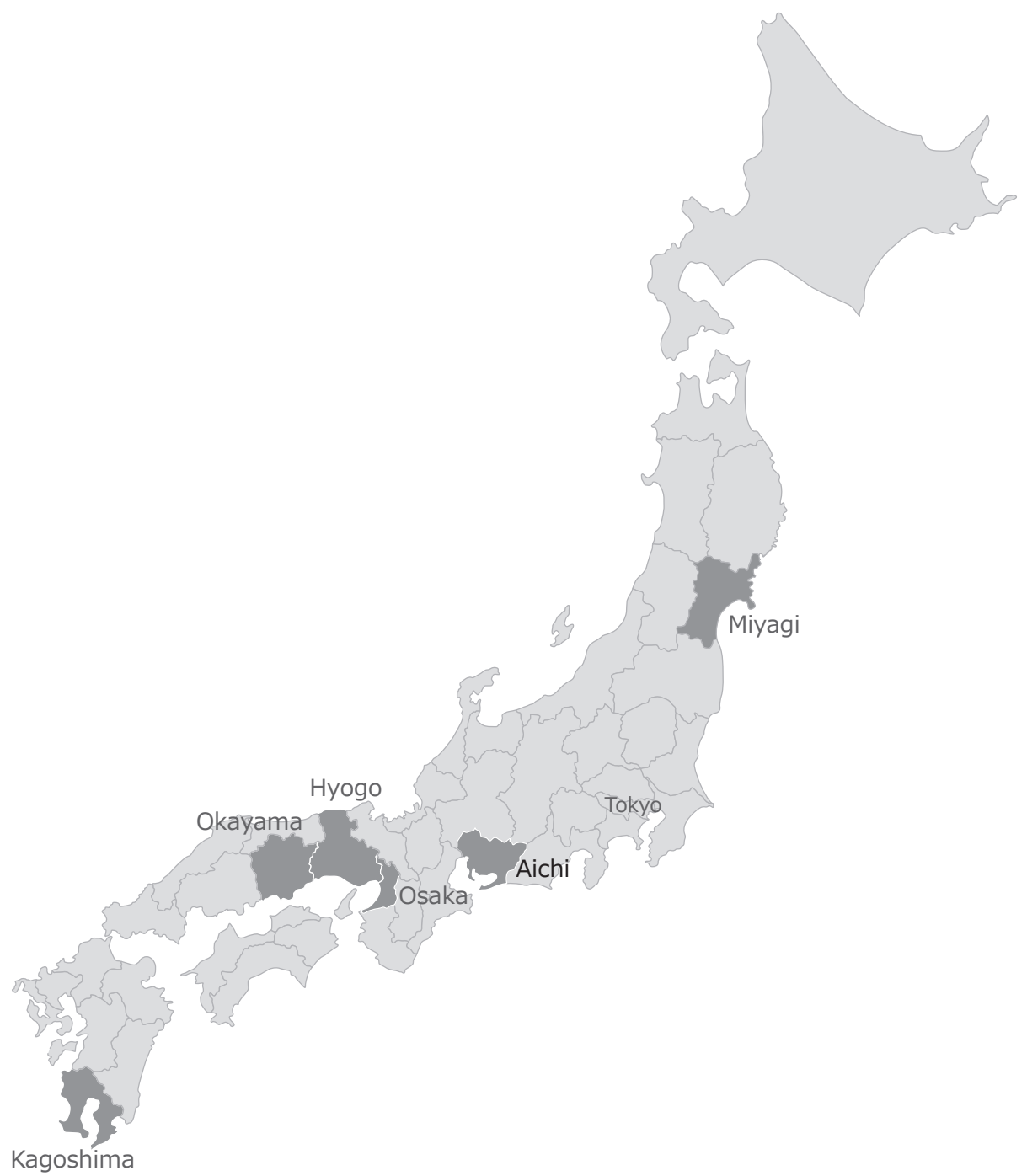

Figure 2. Geographical location of the prefectures sampled in Japan.

Table 1. Questions related to lifestyles included in the questionnaire used in the baseline survey

\begin{tabular}{ll}
\hline Rice/Wheat consumption & Amount/day, Frequency \\
Meat, & Daily/Occasionally/Rare/None/Uncertain \\
Fish and shellfish & Daily/Occasionally/Rare/None/Uncertain \\
Milk and goat milk & Daily/Occasionally/Rare/None/Uncertain \\
Green-yellow vegetables & Daily/Occasionally/Rare/None/Uncertain \\
Miso (soybean paste) soup & Daily/Occasionally/Rare/None/Uncertain \\
Pickles & Every meal/Daily/Occasionally/Rare/None/Uncertain \\
Smoking & Age started \\
& Daily/Occasionally/Never smoked/Uncertain \\
& the numbers of cigarettes smoked a day \\
& ex-smoker: i) the numbers of cigarettes smoked a day \\
& before cessation and ii) years after cessation \\
& The use of Kizami tobacco \\
& The use of other tobacco \\
& Daily/Occasionally/Rare/None/Uncertain \\
& Type: Sake, Shochu, Beer, Whisky, Others, Uncertain \\
Alcohol drinking & Very hot/Moderate/None/Uncertain \\
\hline
\end{tabular}

Table 1 summarizes questions related to lifestyles included in the questionnaire.

\section{Baseline survey}

The questionnaire was distributed among all the residents at the time of the 1965 National Census, which was conducted in October, 1965. Then, they were retrieved, in most cases, by a home visit of public health nurses and midwives who were trained for a standardized method of interview. At the time of home visits, the interviewers reviewed the questionnaires filled in by the respondents, made inquiries to clarify ambiguous answers given in the questionnaire, and tried to get answers for unanswered questions. The interviewers numbered, on average, 50 in each public health district and about 1,500 in total. ${ }^{8}$

The proportion of respondents was $94.8 \%$ of the study area residents identified by the 1965 National Census. Prefecturespecific proportions were 99.8\%, 91.4\%, 91.3\%, 93.8\%, 95.2\% and $99.2 \%$ in the prefectures of Miyagi, Aichi, Osaka, Okayama, Hyogo and Kagoshima, respectively. ${ }^{8}$ Table 2 shows the age and sex distributions of the respondents. ${ }^{1}$

In 1971, an additional survey to collect information on lifestyles was conducted. Dr Hirayama described the results of this survey as follows ${ }^{1}$ : "The information on diet was nearly as stable as that on smoking and drinking. The policy of one-time assessment of risk factors was therefore adopted for practical purposes, and information regarding risk factors obtained at the initial survey was used mostly in this study." 
Table 2. Study population by sex, age group and prefecture

\begin{tabular}{lrrrrrr}
\hline \multirow{2}{*}{ Age, years } & \multicolumn{5}{c}{ Prefectures } \\
& Miyagi & Aichi & Osaka & Hyogo & Okayama & Kagoshima \\
\hline & & \multicolumn{5}{c}{ men } \\
$40-$ & 7,118 & 7,585 & 7,822 & 6,868 & 6,111 & 6,071 \\
$50-$ & 6,924 & 7,706 & 7,922 & 7,256 & 7,040 & 6,630 \\
$60-$ & 5,605 & 5,849 & 7,191 & 5,850 & 6,802 & 5,537 \\
unknown & 12 & 18 & 250 & 24 & 11 & 59 \\
total & 19,659 & 21,158 & 23,185 & 19,998 & 19,964 & 18,297 \\
& & \multicolumn{5}{c}{ women } \\
$40-$ & 8,518 & 9,463 & 9,465 & 8,578 & 7,994 & 8,527 \\
$50-$ & 8,072 & 8,962 & 8,923 & 8,549 & 8,530 & 8,264 \\
$60-$ & 5,867 & 6,021 & 7,399 & 6,042 & 5,947 & 6,164 \\
unknown & 16 & 15 & 414 & 34 & 6 & 87 \\
total & 22,473 & 24,461 & 26,201 & 23,203 & 22,477 & 23,042 \\
\hline
\end{tabular}

\section{Follow-up}

The cohort was followed through the end of 1982. At the beginning of each follow-up year, a migration survey was conducted through reference to the local residence registration. Those who were found to have migrated from the residential public health districts during the previous year were excluded from the mortality follow-up thereafter. During the follow-up period, $8 \%$ of the respondents migrated from the original districts. The deaths were annually ascertained through checking against vital statistics death records kept at each public health center, with the permission of the Ministry of Health and Welfare (Currently Ministry of Health, Labour and Welfare). The causes of death were coded, using the 7 th Revision of the International Classification of Diseases. ${ }^{8}$ The information on lifestyles and other factors obtained from the baseline survey for each individual was assembled at the central office and filed systematically by residence and by date of birth. Name cards with address and key numbers were also used to help manual matching. ${ }^{1}$

\section{MAJOR PUBLICTIONS}

\section{Second-hand smoke exposure and cancer risk}

In 1981, Dr Hirayama reported an association between secondhand smoke exposure and lung cancer risk. More precisely, Hirayama Cohort Study showed that nonsmoking women married to smokers had a higher lung cancer mortality than did nonsmoking women married to nonsmokers. 9 "Hirayama is generally credited with publishing the first evidence linking passive smoking and lung cancer" as pointed out by an article published in Bulletin of the World Health Organization in 2000. ${ }^{10}$ Hirayama Cohort Study is one of the most cited studies on this topic. The citation of the Hirayama paper amounted to 575 as of March, 2019 (Web of Science, Clarivate Analytics). His report was one of three spearheading epidemiological papers on the association. The other two articles were reported by Dr Dimitrios Trichopoulos and his colleagues from Greece, and Dr Lawrence Garfinkel and his colleagues from the USA. ${ }^{11,12 ~ " W h i l e ~ b o t h ~}$ studies showed an elevation in the point estimate of lung cancer risk associated with passive smoking, Garfinkel's study did not reach statistical significance."10 Upset by Hirayama's study, tobacco industries tried to discredit his study results, mobilizing scientists friendly to the industry. ${ }^{13-15}$ As we all know, their attempts were unsuccessful. Needless to point out, Hirayama's study was scientifically sound, as described by Sir Richard Doll, a British physician at Oxford University who did pioneering studies linking cigarette smoking and lung cancer. ${ }^{16}$ The evidence obtained from more than 50 additional epidemiological studies has confirmed the 1981 findings on the association between second-hand smoke exposure and lung cancer. ${ }^{17}$ In 1984, Dr Hirayama reported that the mortality of cancers other than lung cancer was also increased among nonsmoking women with smoking husbands. ${ }^{18}$ Recent meta-analysis of 4 cohort studies including Hirayama Cohort Study and 5 case-control studies estimated that the pooled relative risk of lung cancer associated with second-hand smoke exposure was 1.28 (95\% confidence interval: $1.10-1.48) .{ }^{19}$

In the 1990s, a new cohort study (the Japan Public Health Center-based Prospective Study; JPHC study) was initiated by the National Cancer Center Japan and its collaborators. This study includes areas in Okinawa and Shikoku Islands, which were not covered by Hirayama Cohort Study. It confirmed that secondhand smoke exposure was a risk factor for lung carcinoma among Japanese women, ${ }^{20}$ and the association was most evident for adenocarcinoma. In the most recent and extensive pooled analyses of 18 case-control studies, which was conducted by International Lung Cancer Consortium (ILCCO), the association between second-hand smoke exposure and adenocarcinoma was statistically significant, but its magnitude was not as large as that for other histological types. ${ }^{21}$ Different effects of second-hand smoke exposure on different histological types of lung cancer remain to be solved.

\section{The associations of smoking and drinking with cancer mortality}

Hirayama Cohort Study quantified the risk of cancer and other diseases in relation to tobacco smoking. "This study was large and unique in that it involved a non-Caucasian" as described by IARC monographs volume 83 on tobacco smoke and involuntary smoking. ${ }^{22}$ Dr Hirayama reported major findings of the cohort study at several important scientific conferences. ${ }^{23-26}$ The results of comprehensive analysis using Poisson regression analysis of grouped data on cancer mortality in relation to cigarette smoking were reported in $1990 .{ }^{27}$ Regarding alcohol drinking, Dr Hirayama summarized major findings, and also described interactions between smoking and drinking on cancer risk. ${ }^{28,29}$

\section{Dietary habits and cancer mortality}

Hirayama Cohort Study revealed decreased risks of certain cancers in association with green and yellow vegetable consumption. $^{28,30,31}$ In addition, the study found a relationship of soybean paste soup intake to gastric cancer risk. ${ }^{32}$ The other studies that should be mentioned here are those conducted by the collaboration with epidemiologists of Oxford University including Sir Richard Doll. One of them is on esophageal cancer mortality in relation to hot tea drinking, alcohol drinking, tobacco use and dietary habits. ${ }^{33}$ The other is on possible protective effect of milk, meat and fish for cerebrovascular disease mortality. ${ }^{34}$

\section{HISTORICAL IMPACT ON CANCER EPIDEMIOLOGY}

The results obtained from Hirayama Cohort Study ${ }^{1}$ showed that the population attributable fraction in men due to daily smoking were $17.5 \%$ for all causes, $32.3 \%$ for cancer, $71.5 \%$ for lung 
cancer in Japan, in which the proportion of smokers among adult men was as high as $84 \%$ in 1966. The proportion declined steadily since that time; the decline sped up from 1995, and the proportion of smokers among men was under 30\% in 2017 (about $8 \%$ for women). However, the health burden of smoking is still large among Japanese men as indicated by following pooled analyses of the large-scale cohort studies in Japan. ${ }^{35,36}$

The invaluable information obtained from Hirayama Cohort Study served as guidelines for primary prevention of cancer and other non-cancer diseases. The most important contribution of this study in the field of public health is the world-wide spread of smoking ban in indoor public venues and workplaces. Hirayama's BMJ paper and subsequent accumulation of scientific evidence led to Article 8 of the WHO Framework Convention on Tobacco Control, which was implemented by the unrelenting efforts of people who devoted their lives to tobacco control.

It should also be noted that Hirayama Cohort Study inspired many Japanese epidemiologists. For example, the Japan Collaborative Cohort Study (JACC study) and the JPHC study can be regarded as products of such epidemiologists. The website of Japan Epidemiology Association (http://jeaweb/jp/english/ activities/cohort.html/) has the list of various cohort studies conducted in Japan.

Hirayama's work also stimulated epidemiological activities outside Japan. In India, for example, Dr Gangadharan who got an IARC scholarship with the help of Dr Hirayama and did Master of Science in Statistics at University of Pittsburgh in the 1960s, started a large-scale cohort study in Karunagappally Taluk in Kerala, south India in 1990. He was also a person inspired by Hirayama Cohort Study. The baseline survey of this cohort collected information on socioeconomic factors, lifestyles and other factors of 359,619 residents, which correspond to $93 \%$ of Karunagappally population in $1991 .{ }^{37} \mathrm{He}$ and Dr Jayalekshmi, his colleague, published a number of important papers on smoking and cancer. ${ }^{38-40}$

In conclusion, Hirayama Cohort Study is one of the most influential cohorts in Japan and globally.

\section{ACKNOWLEDGMENTS}

Conflicts of interest: None declared.

\section{REFERENCES}

1. Hirayama T. Life-style and mortality: A large-scale census-based cohort study in Japan. In: Heidelberg JW, series editor. Contributions to Epidemiology and Biostatistics. Vol. 6. Karger; 1990.

2. Doll R, Peto R. Mortality in relation to smoking: 20 years' observations on male British doctors. BMJ. 1976;ii:1525-1536.

3. Hammond EC, Horn D. Smoking and death rates; report on fortyfour months of follow-up of 187,783 men. I. Total mortality. $J$ Am Med Assoc. 1958;166:1159-1172.

4. Kahn HA. The Dorn study of smoking and mortality among U.S. veterans: report on eight and one-half years of observation. Natl Cancer Inst Monogr. 1966;19:1-125.

5. Weir JM, Dunn JE Jr. Smoking and mortality: a prospective study. Cancer. 1970;25:105-112.

6. Best EW, Walker CB, Baker PM, Delaquis FM, McGregor JT, McKenzie AC. Summary of a Canadian study of smoking and health. Can Med Assoc J. 1967;96:1104-1108.

7. Hirayama T. Diseases and Life Style: A Large-scale Cohort Study in Japan. J Epidemiol. 1992;2(2sup):37-52.

8. Mizuno S, Akiba S, Hirayama T. Lung cancer risk comparison among male smokers between the "Six-prefecture cohort" in Japan and the British physicians' cohort. Jpn J Cancer Res. 1989;80:11651170.

9. Hirayama T. Non-smoking wives of heavy smokers have a higherrisk of lung cancer: a study from Japan. BMJ. 1981;282:183-185.

10. Ong E, Glantz SA. Hirayama's work has stood the test of time. Bull World Health Organ. 2000;78:938-939.

11. Trichopoulos D, Kalandidi A, Sparros I, MacMahon B. Lung cancer and passive smoking. Int J Cancer. 1981;27:1-4.

12. Garfinkel L, Auerbach O, Joubert L. Involuntary smoking and lung cancer a case-control study. J Natl Cancer Inst. 1985;75:463-469.

13. McGarity TO. The prospect of "Daubertizing" judicial review of risk assessment. Law Contemp Probl. 2003;66(4):155-226.

14. McGarity TO. Defending clean science from dirty attacks by special interests. In: Wagner W, Steinzor R, editors. Rescuing Science from Politics: Regulation and the Distortion of Scientific Research. Cambridge: Cambridge University Press; 2006:30.

15. Lee P. "Marriage to a smoker" may not be a valid marker of exposure in studies relating environmental tobacco smoke to risk of lung cancer in Japanese non-smoking women. Int Arch Occup Environ Health. 1995;67:287-294.

16. Altmanjan LK. Cancer study reports high risk for wives of smoking husbands. NY Times January 16, 1981; https://www.nytimes.com/ 1981/01/16/us/cancer-study-reports-high-risk-for-wives-of-smokinghusbands.html. Accessed March 26, 2019.

17. A report of the Surgeon General. The health consequence of smoking, Cancer 1982. U.S. Department of Health and Human Services. Office on Smoking and Health, Rockville, Maryland. (https://www.surgeongeneral.gov/library/reports/secondhandsmoke/ chapter7.pdf) Accessed March 26, 2019.

18. Hirayama T. Cancer mortality in nonsmoking women with smoking husbands based on a large-scale cohort study in Japan. Prev Med. 1984;13:680-690.

19. Hori M, Tanaka H, Wakai K, Sasazuki S, Katanoda K. Secondhand smoke exposure and risk of lung cancer in Japan: a systematic review and meta-analysis of epidemiologic studies. Jpn J Clin Oncol. 2016; 46(10):942-951.

20. Kurahashi N, Inoue M, Liu Y, et al. JPHC Study Group. Passive smoking and lung cancer in Japanese non-smoking women: A prospective study. Int J Cancer. 2002;122:653-657.

21. Kim CH, Lee YC, Hung RJ, et al. Exposure to secondhand tobacco smoke and lung cancer by histological type: a pooled analysis of the International Lung Cancer Consortium (ILCCO). Int J Cancer. 2014;135(8):1918-1930.

22. IARC Working Group on the Evaluation of Carcinogenic Risks to Humans. Tobacco smoke and involuntary smoking. In: IARC Monographs on the Evaluation of Carcinogenic Risks to Humans. Vol. 83. Lyon: World Health Organization, the International Agency for Research on Cancer; 2004.

23. Hirayama T. Prospective studies on cancer epidemiology based on census population in Japan. In: Proceedings of XI International Cancer Congress. Florence. Cancer Epidemiology and Environmental Factors, 3. Amsterdam: Excerpta Medica, 1975:26-35.

24. Hirayama T. Epidemiology of lung cancer based on population studies. In: Clinical implications of air pollution research. Chicago: The American Medical Association; 1976:69-78.

25. Hirayama T. Smoking and cancer. A prospective study on cancer epidemiology based on census population in Japan. In: Proceedings of the 3rd World Conference on Smoking and Health 1975. Washington: Department of Health Education and Welfare Publication No. (NIH) 77-1413, 1977:65-72.

26. Hirayama T. Prospective studies on cancer epidemiology based on census population in Japan. In: Nieburgs HE, ed. Third International Symposium on Detection and Prevention of Cancer. Part 1. volume 1. New York: Marcel, Dekker; 1977:1139-1148.

27. Akiba S, Hirayama T. Cigarette smoking and cancer mortality risk in Japanese men and women-results of from reanalysis of the six-prefecture cohort study data. Environ Health Perspect. 1990;87: 19-26.

28. Hirayama T. A large-scale cohort study on cancer risks by diet- 
with special reference to the risk reducing effects of green-yellow vegetable consumption. Princess Takamatsu Symp. 1985;16:41-53.

29. Hirayama T. Association between alcohol consumption and cancer of the sigmoid colon: observations from a Japanese cohort study. Lancet. 1989;2(8665):725-727.

30. Hirayama T. Nutrition and cancer-a large-scale cohort study. Prog Clin Biol Res. 1986;206:299-311.

31. Hirayama T. Life-style and cancer: from epidemiological evidence to public behavior change to mortality reduction of target cancers. J Natl Cancer Inst Monogr. 1992;(12):65-74.

32. Hirayama T. Relationship of soybean paste soup intake to gastric cancer risk. Nutr Cancer. 1982;3:223-233.

33. Kinjo Y, Cui Y, Akiba S, et al. Mortality risks of oesophageal cancer associated with hot tea, alcohol, tobacco and diet in Japan. J Epidemiol. 1998;8:235-243.

34. Kinjo Y, Beral V, Akiba S, et al. Possible protective effect of milk, meat and fish for cerebrovascular disease mortality in Japan. J Epidemiol. 1999;9:268-274.

35. Katanoda K, Marugame T, Saika K, et al. Population attributable fraction of mortality associated with tobacco smoking in Japan: a pooled analysis of three large-scale cohort studies. J Epidemiol.
2008;18(6):251-264.

36. Inoue M, Sawada N, Matsuda T, et al. Attributable causes of cancer in Japan in 2005 - systematic assessment to estimate current burden of cancer attributable to known preventable risk factors in Japan. Ann Oncol. 2012;23:1362-1369.

37. Jayalekshmy PA, Akiba S, Nair MK, et al. Bidi smoking and lung cancer incidence among males in Karunagappally cohort in Kerala, India. Int J Cancer. 2008;123:1390-1397.

38. Jayalekshmi PA, Gangadharan P, Akiba S, Nair RR, Tsuji M, Rajan B. Tobacco chewing and female oral cavity cancer risk in Karunagappally cohort, India. Br J Cancer. 2009;100:848-852.

39. Jayalekshmi PA, Gangadharan P, Akiba S, Koriyama C, Nair RR. Oral cavity cancer risk in relation to tobacco chewing and bidi smoking among men in Karunagappally, Kerala, India: Karunagappally cohort study. Cancer Sci. 2011;102(2):460-467.

40. Jayalekshmi PA, Nandakumar A, Akiba S, Gangadharan P, Koriyama C. Associations of tobacco use and alcohol drinking with laryngeal and hypopharyngeal cancer risks among men in Karunagappally, Kerala, India -Karunagappally cohort study. PLoS One. 2013;8:e73716. 